\title{
At Work in the Fields of the True
}

\author{
Charles Travis | ORCID: 0000-0003-2370-7685 \\ Department of Philosophy, King's College London, London, UK \\ Universidade do Porto, Porto, Portugal \\ c.s.travis@gmail.com
}

\begin{abstract}
This essay outlines a certain 2oth century Oxonian tradition in epistemology, contrasting it with another line of thought set out by Michael Ayers. The tradition begins with Cook Wilson and the idea that knowing is never having evidence, no matter how strong. It takes a turn in J.L. Austin, introducing two ideas into philosophy: disjunctivism and occasion-sensitivity. The last section considers whether either can really live without the other. The first part of the essay is a general consideration of the relation between two forms of awareness: perceptual, and 'propositional' (awareness-that), and of how the first may furnish proof of the second. The second part considers Ayers' view of the relation, particularly as expressed in his idea of primary and secondary knowledge, and its relation to disjunctivism about knowledge.
\end{abstract}

\section{Keywords}

proof - awareness - disjunctivism - evidence - generality

There is a conception of knowing which is peculiarly Oxonian. It stems from Cook Wilson, was transmitted by H.A. Prichard to J.L. Austin, thence to J.M. Hinton, followed by Paul Snowdon and John McDowell. Michael Ayers, Oxonian 'in hart en nier', takes a different turn. What follows concerns the difference that difference makes.

Cook Wilson's idea (1926, 99-100) starts here:

In knowing we can have nothing to do with the so-called 'greater strength' of the evidence ... simply because we know that this 'greater 
strength' of evidence of A's being B is compatible with A's not being B after all.

And it continues with Prichard (1950, 87):

Knowing is not something which differs from being convinced by a difference of degree of something ... Knowing and believing differ in kind ... Their difference ... is not that of species and genus ... To know is not to have a belief of a special kind ... and no improvement in a belief ... will convert it into knowledge.

To know, the idea is, is to have proof, what rules out absolutely things being otherwise. One sees, grasps, how it is that things cannot be otherwise (even if they could, or might, have been). Knowing is never merely Locke's 'all the certainty our frame requires'.

Mathematics provides paradigms. One grasps a proof that there is no largest prime, sees how it proves. One thus sees how it is that there cannot be such. Such, the tradition has it, is proof überhaupt, not just in mathematics.

Just here the rub. For, as Frege (1918, 73, my translation) put it,

By the step by which I win myself an environment I expose myself to susceptibility to error.

In mathematics, perhaps, if I genuinely appreciate the proof, my susceptibility to error is thereby cancelled. But in spatiotemporal, or sublunary affairs, how could my undoubted susceptibility (in principle) to error ever be cancelled absolutely? How could, e.g., seeing supply me things to judge, in judging which I simply could not be going wrong? So how could (sublunary) knowledge ever admit of proof on an understanding of, and on a par with, that notion of proof which finds a place in mathematics?

Cook Wilson and Prichard seem to have thought that where sublunary thought carries susceptibility to error (for them not always), such is not cancellable. With Austin, however, the tradition took a different turn. Austin, with Frege, recognised that susceptibility (in principle) to error was a condition on having things to think überhaupt. So, in Wittgenstein's image, he 'rotated things around the axis of our real needs', so that seeing the pig before one can furnish proof that there is a pig before him, cancelling susceptibility to error, just as thoroughly as proof in mathematics.

In rough outline Austin's turn looks like this: Given a pig's presence on Benno's sofa it is anyway true that there is a pig on Benno's sofa. A transition 
from first-mentioned to second is anyway a transition to truth, a truth which, given it, there could not but be. That porcine presence may thus count as grounding that truth, perhaps of the grounds of it (though there may also be grounds for counting that being as a pig). Where it does so count, where it is visible (perceivable) porcine presence (and recognisable for what it thus is) it may also thus be proof. Where there is such proof it is fully on a par with mathematical proof. Given such (recognisable) presence, there cannot but be such proof. There is no possibility of things being otherwise. But all the mays here matter. The mere porcine presence itself, while it makes for truth, need not make for proof. What is recognisable is more than just likely to be (in some way) negotiable.

Thus, where perceptual awareness of the pig's presence may make that presence proof that a pig is present, the mathematical paradigm applies. Proof remains proof throughout. The pig's presence grounds the truth just as surely as the construction of a larger prime from any given set of such grounds the truth that there is no largest prime. To grasp either as the grounds it is is to understand why, or how, things cannot be otherwise. What follows is largely an elaboration of this last idea.

Two aspects of Ayers' view will receive particular attention here. First, with the tradition from Austin on, Ayers treats perception as a source of proof (at least de facto incontrovertible). But, missing the Austinian turn, he works a distinction Austin draws into a quite different one between what he terms 'primary' and 'secondary' knowledge, thus losing the Cook Wilsonian point that knowledge does not come in grades. Second, Ayers dissents from disjunctivism about knowledge - a natural development of Austin's turn, from Hinton to John McDowell and Paul Snowdon. His dissent, I will suggest, is misunderstanding, but certainly not proprietary such. So confining myself, I will miss much right and salubrious in Ayers' book.

\section{Die Trennung}

Two ideas of Frege's will matter here: first, that of separating out the logical from the psychological, being true (Wahrsein) from holding true (Fürwahrhalten); second that of two sorts of proof, only one of which concerns logic. The first occurs as one of the three most basic rules which are to govern Grundlagen (Frege 1884, 3, my translation):

$[\mathrm{O}]$ ne has to separate the question how we arrive at the content of a judgement from that of the grounds for our assertion of it. 
And again in 1897 (157, my translation) thus:

For the success of a scientific investigation it is not inessential that one not mix it with questions which can be treated independently by others ... So we shall not bother about how thinking and the gaining of conviction really occur. It is not holding true which concerns us but rather the laws of being true.

The business purely of being true is to be studied independent of any truck thinkers may have with it, either as sources of content, or as engagers in representing (truly or falsely). I will call this separation die Trennung. For Frege it is just normal good scientific practice. To find the law-like behaviour of a phenomenon one needs to locate the right law-abiding protagonists: for mechanics the right physical quantities; for logic the right truth-bearers - those with precisely those features on which truth or falsehood depends, thus those which, if true are the truth there thus is, if false, the falsehood. Frege calls these 'Gedanken'. One might say 'thinkable', or just 'truth-or-falsehood'. Two Gedanken differ only in how the way things are would matter to things being as each represented this. A Gedanke/thinkable is thus a truth-bearer with no features which might identify a content-bearer.

For Frege it is whole thoughts first. If there are to be laws of truth, whole thoughts must be decomposable. But each sort of element in a decomposition is to be defined in terms of its role within a whole thought (i.e., contribution to when that whole thought would be true, thus to how it represented things as being). An element in a decomposition is thus a partial doing of what that whole thought does. The whole thought making truth turn in a determinate way on how things are, such a proper part makes truth turn in part in some given way on how things are. What a proper part does thus can be done at all only in the context of a whole decomposition. (Truth cannot turn simply on Sid, nor on who drinks.)

Frege insists that a whole thought is multiply decomposable. So, a decomposition of a thought identifies what thought this is only given a criterion of identity: what determines when another decomposition would count as of that thought. Thus Frege (1906, 203, my translation) writes,

The singularity of a [singular] thought belongs to it, really, not as such but rather only with reference to a possible way of decomposing it. It is possible that the same thought [decomposed as singular] can appear as particular with respect to another decomposition.... 
A thought is not per se to be generated (only) by some fixed stock of elements, by some fixed stock of rules. So it cannot have a syntax as the sentences of a language do. To repeat, a thought is not a content-bearer, but rather (if you like) a content to be borne.

The main point of die Trennung for present purposes is that, in a Gedanke/ thinkable we have something to which thinkers may bear an attitude or stance, or enjoy a status (notably here knowledge) which carries with it no presuppositions per se as to the conditions under which a thinker might count as so relating, or under which two thinkers might count as both so relating. As the literature makes clear, the temptation to assumptions in such matters is enormous. Against which we need constantly to recall that the business of being true is not that either of taking for, or that of taking in as, true.

\section{$2 \quad$ Truth's Origin}

The phenomenon of being true arises together with another, that of representing-as. A thought (Gedanke) represents things in general as some way for them to be. Things may or may not so be, for all that they are so represented. If so, truth, if not, not. (Vide Aristotle.) Representing-as, the thought's business, thus contrasts with, e.g., the sort of representing in which the bags under Sid's eyes may represent a long and sleepless night (if no such night, such is not what they represent). A thought has generality. Things need not have been just as they are, for all of which there would still have been the thought (say, that Sid is out of shape), which might still be either true or false (the way things would then have been or not).

Every (whole) thought represents the same thing to be some way, to wit, things in general. Otherwise it would not be a whole thought, but rather a proper predicative thought-part. Thoughts vary only in how they represent things (being). What is thus represented as some way has no generality. It would not have been the way things are, were things not precisely as they are. Representing-as is thus a two-party enterprise in which (in the whole thought case) truth (or falsehood) arises. It is thus an interaction between a generality, the thought, with its depiction of the way things are, and a particular case, the depicted, aka the way things are. The thought's role in this enterprise is to determine when things would be as represented - in a way which determines whether they are. The role of the depicted is simply to be that of which such would thus be determined. The objectivity of truth requires the enterprise to be precisely thus two-party. Otherwise, Aristotelean platitudes lapse, and with them objectivity. 
As Frege insists, any decomposition of a thought must contain at least one proper element (not itself a thought) in that same business, representingas. Not itself a thought, it cannot represent things in general as some given way. Whatever it can so represent is an object (to logic's eye). That is, to be an object (in logikgemäss sense) just is what can so complete a proper predicative subthought.

In sum, truth comes in question just where something is represented as being some way-to-be. There is truth just where that something's being as it is is, or counts as, something being that way-to-be. Whether this is so depends only on what way-to-be the one in question is. But that something so represented need not have been just as it is. The way-to-be in question would have remained just the same for all that. How can it thus speak to what there need not have been at all?

\section{3}

\section{Aloofness}

Is this last a pseudo-problem? In 1882 (164, my translation) Frege wrote to Marty (or Stumpf):

You stress separating out the judging from the matter judged. Still more important, it seems to me, is distinguishing the particular thing from the concept.

Though Frege had not then yet clearly decided what a concept was to be, at any rate it belongs on the representer side of representing-as, either as what predicates (of an object), or as the content thereof. So it generalises as do a thought, or a way for things, or a thing, to be. Frege's point is that in that role it is crucial for a concept not to relate to what falls under it (what is what it is a concept of being) as does a designator to its designatum.

Such is, for a start, a demand on playing either of the just-mentioned parts in representing-as. For, for this it must be possible to represent something as falling under a concept (being what it is a concept of) even when that thing does not so fall - the possibility of representing falsely. Sid need not be debonair to be so represented. Whereas if a designator is to make an object the one represented as, e.g., debonair, it must stop nowhere short of having that item as designatum.

Such is also needed if the thought (Gedanke) is to play its role in making sense of the notion proof. To use Frege's example (1914), if all humans are mortal, does it follow that Cato is? To logic's eye (one hopes), no. A piece of 
information is missing: that Cato is human. (A serious oversight had robotics then reached an advanced enough state.) But if human designated, albeit quite polysemously, there would have been no missing information. For Cato is (was) human, thus would have been one thus named.

So a slogan might be: A concept proposes, the world disposes. The concept determines when a thing would be what the concept is of, what would count as a case of being what it is of. The way things are then does the rest. Such is aloofness.

Given aloofness, a concept is not identified by its extension as the concept it is. Imagine that there is a concept, F, of which all that is given is that a certain object, $\mathrm{v}_{1}$, falls under it. There is so far no saying what concept $\mathrm{F}$ is (what it is of). Suppose it is further given that another object, $\mathrm{v}_{2}$, falls under it (casu quo does not). You are so far no better off. Now go on in the same way. Neither extension nor counter-extension identifies the concept as the one it is - not even if it is stipulated that such is the extension. (Being the square of 39 and being 1521 are usually counted as two different ways for an object to be.)

But such independence of a concept from its extension goes with a converse point. There are relations which hold between two concepts merely by what it would be to satisfy each: containment (whatever satisfied the one would eo ipso satisfy the other), overlap (something might satisfy both), exclusion (what satisfied the one would eo ipso not satisfy the other). Thus relations definable in terms of entailment, conjunction, negation. Suppose there are two concepts, $\mathrm{F}$ and $\mathrm{G}$, about which all that is given is that they relate to each other in some particular such way: whatever is $F$ is also $G$, or eo ipso not $G$, or etc. So far there is no saying which concept either is (what either is of). We are, so to speak, spoilt for choice. Now we add another concept, $\mathrm{H}$, about which all that is given is how it thus relates to F and to G. Still spoilt for choice. Now go on in the same way. The upshot: No formal structuring of any fixed set of concepts (at least countable or less) fixes as such which concept any of these is. At least in sublunary affairs, any formal structuring of given concepts (in terms of entailment, negation, etc.) leaves it open for the world (what representing-as depicts) to have a say as to which concepts these are. The conceptual does not take care of itself. Call this its informality. (Cf. Putnam 1977) Such has important application when it comes to understanding definition.

\section{Two Sorts of Proof}

In an undatable series of remarks Frege (Kernsatz 13, undated, 190, my translation) writes: 
One justifies a judgement either by going back to already recognised truths, or without appeal to other judgements. Only the first case, consequence, is logic's object.

Suppose there is a consistent set of thoughts and a thought, and that set relates to that thought thus: were all in the set true, so, too, would be that thought. Call such a relation truth-transmitting. Also call a transition from such a set to a thought so related truth-transmitting. Then proof by truth-transmission - a sequence of truth-transmitting transitions - is Frege's first case, logic's object.

Such proof is, of course, a proper part of the domain of truth-transmitting sequences. At least two other conditions need to be satisfied for such a sequence to be a proof. As Frege puts it, a proof must start from acknowledged truths. So those just-mentioned sets of thoughts - the origins of the transitions in the sequence - must be either already recognisably true (or so to be taken), or termini of prior transitions in the sequence. Further, each transition must be recognisably truth-transmitting.

The laws of truth (logic's laws) are laws of truth-transmission. Where a transition in a sequence is licensed by some such (basic) law, such may count for many purposes as the required recognisability. Such is one standard by which to demarcate that subdomain of (sequences of) truth-transmissions which is proof. (No claim is made here that there is a unique way of thus locating a subdomain.)

What might the other sort of proof be - that which logic does not treat? How else might a proof work than by truth-transmission? One suggestion: Suppose there were something which was ineligible for truth or falsehood (e.g., my left shoe). It could not transmit truth, since it has none to transmit. But it might confer, or yield, truth. In which case it might so relate to some given truth. It might be that for that thing to be as it is is for some given truth or falsehood to be true: given this first, this last. Call such a relation truth-yielding. Suppose there is a concept, say, being a truffle, and for something to be as that object at the centre of the meatball is, would be for it to be a truffle. Then that object at the centre stands towards the concept truffle in a truth-yielding relation.

Again, proofs by truth-yielding, if any, will form a proper subdomain of the domain of truth-yieldings. Something here must correspond to the requirement that a proof by truth-transmission must start from acknowledged truth. At least for the cases which will concern us here, I suggest that it must be recognisably present (or recognisably exist). Then there must be a requirement that the transition from what is innocent of truth to the relevant truth must be recognisably truth-yielding. 
Prima facie perception is a rich source of proof meeting these demands. Entering Benno's salon Pia encounters his pet pig, Ilse, asleep on the sofa. This porcine presence, while neither true nor false, does stand in a truth-yielding relation to, among others, the Gedanke that there is a pig on the sofa. Given that Ilse is visibly on the sofa, the condition corresponding to acknowledged truth in truth transmission is satisfied. Given that in these circumstances one can tell a pig by its appearance, and hence on sight, the condition corresponding to recognisable truth-transmission is satisfied. Given that Pia sees Ilse on the sofa and (in these circumstances) knows a pig when she sees one, seeing Ilse on the sofa can be proof for Pia that a pig there sleeps.

A caveat. Few seriously believe that to be a pig is to look like one. There can be proof of the kind just scouted. But that Ilse looks as (here) only a pig would is not in general what grounds the truth that the item on the sofa is a pig (the object of the relevant awareness-that). So there remains the question when perceptual awareness would supply proof that a pig is before one, and on what whether it does might depend; questions, answers to which might depend on circumstance.

\section{$5 \quad$ Perceptual Awareness}

Proof of the second kind need not start from perceptual awareness. But where it does, it mediates a transition from one form of awareness to another, awareness-that. Truth-transmission - transition between objects of awarenessthat - is the natural home of law-likeness. We now stand outside this, in the realm of transitions between different forms of awareness. For a clear view of these we must start with a clear view of perceptual awareness.

First, the object of perceptual awareness on an occasion is roughly spatiotemporally bounded. It is awareness of proper parts of the careers of what is before the eyes, heard, touched. In the visual case it is restricted to what is visible of what is before the eyes. One does not, in general, see all of what is seen. But, so far as it reaches, it is awareness of how things are, or are transpiring, in the relevant region - of things being as they are, something irreducible to their being such-and-such ways.

Second, in the business of representing-as an object of perceptual awareness is always on the side of the depicted, something for the representing to bring under a generality, a particular case. It never plays the role of the generality under which, in the representing, a particular case is being brought. (A generality, and its proprietary way of generalising, are, as Frege insists, invisible, 
that is, not objects of sensory awareness.) An object of perceptual awareness is never eligible for truth or falsehood.

Third, perceptual awareness, like its object, is episodic, temporally extended. It is coextensive with the episode thus witnessed. It is intrinsically au courant. Should it be intermittent, the intervals in which it lapses are intervals in which (temporal) bits of the careers just witnessed are missed. By contrast, should awareness-that be intermittent (temporary lapses of memory), the object of awareness remains untouched. Accepting Benno's invitation, Pia forgets for the instant that her nephew Tristan is due for the weekend, remembering ruefully a moment later. Turning her gaze away from Sid for a moment she misses, irretrievably, his missing his mouth with his glass.

Fourth, objects of perceptual awareness contrast with truth-transmitters in being intrinsically whatever proof they may be. The contrast is as follows. A thought fills the role of truth-transmitter. To do this it need not be true, but only truth-valued (or evaluable). Truth-transmission is a matter of what would be so were it true. It need be true only where the transmission in question is to be proof. By contrast, for an object of perceptual awareness to be a term in a truth-yielding relation it needs precisely to be something there is of which to be perceptually aware. Perceptual awareness, so far as it extends, is of things being as they are. No more is required of such an object of awareness for it to be truth-yielding just where it is. It, just in being as it is, is already a particular case of whatever ways for things to be it instances.

A thought, for all of its being the very thought it is, must still achieve a further status before it can transmit truth. Its mere existence does not ensure that particular case, the way things are, to instance its generality. Truth-transmission must thus distinguish between two statuses, truth and falsehood, which a thought might enjoy. An object of perceptual awareness need - and can - only be the very item that it is for yielding precisely and only all the truth it does. There are thus no two further status for it to enjoy corresponding to the difference between a true and a false thought (the one representing things as they are, the other as they are not). (Of course, just as with truth-transmission, there are further requirements for truth-yielding to be proof. As said already, these may not, and sometimes cannot, be met by objects of perceptual awareness. You cannot always tell a pig by its looks.)

$\mathbf{5 . 1}$

\section{A Note}

Objects of perceptual awareness and object of awareness-that are disjoint categories. An object of awareness-that is eo ipso invisible, not an eligible object of perceptual awareness (just as an object of perceptual awareness is not eligible for truth or falsehood - unless, as Frege puts it $(1918,59)$, an Absicht attaches 
to it: it is to be understood as representing things as being thus and so. If Sid drinks, you can watch, witness, him so engaged. But you cannot watch, look at, witness, glance at that Sid drinks. Such is not an object of sight. (As Frege put it $(1918,61)$, it emits no rays which form images on retinas.) The verb 'see', on one use, precedes a that-clause. 'I see that Sid is drinking again.' But what this tells us is that the object of 'see', on this use, is not an object of perceptual awareness. (It is not uncommon that visual imagery should be applied, qua imagery, to thought. The word 'idea' is one example, as is 'look' in, e.g., 'Look. This is my final offer. Take it or leave it.)

The object of 'see (that)' is, trivially, that such and such. 'See', so used, thus speaks of awareness-that, mere shades away (at most) from 'recognise', 'be aware/apprised', 'realise' followed by 'that'. The success achieved here suggests a status enjoyed rather than an attitude held. Sometimes, far from always, 'see that' may carry a suggestion of visual aetiology: Sid sees that John has a new motor because he sees the motor. In any case, seeing that $\mathrm{P}$ does not supply grounds on which to judge that P. It depends on such grounds, so far unspecified.

\section{Primary and Secondary}

An example of Austin's (1962, 115):

The situation in which I would properly be said to have evidence for the statement that some animal is a pig is that, for example, in which the beast itself is not actually on view, but I can see plenty of pig-like marks on the ground outside its retreat. If I find a few buckets of pig-food, that's a bit more evidence, and the noises and the smell may provide better evidence still. But if the animal then emerges and stands there plainly in view, there is no longer any question of collecting evidence; its coming into view doesn't provide me with more evidence that it's a pig, I can now just see that it is, the question is settled.

Austin's point here is that objects of perceptual awareness are not invariably mere evidence for an object of awareness-that; they can, on occasion, be proof. Seeing the pig can make it proof that there is a pig about. It can thus confer knowledge, as (vide Cook Wilson) mere evidence never does.

A prelude to the Austinian turn. But being a pig is one thing, looking just like one another. So wherever one in fact sees a pig, it is always conceivable that such should leave him in need of further proof (from looks to fact) before 
he has proof that he sees a pig. Austin's answer to this (the turn) is that what is conceivable must be distinguished from what might be. Thus $(1946,170)$ :

[B]eing aware that you may be mistaken doesn't mean merely being aware that you are a fallible human being; it means that you have some concrete reason to suppose that you may be mistaken in this case. Just as 'but I may fail' does not mean merely 'but I am a weak human being' ... It is naturally always possible ('humanly' possible) that I may be mistaken or may break my word, but that by itself is no bar against using the expressions 'I know' and 'I promise' as we do use them.

For Cook Wilson and Prichard it was fine if one could never know that he stood before a pig. For Austin such will not do. Seeing a pig can sometimes be proof, even if there might be other times when it would not be. The relation between perceptual awareness and awareness-that is not inherently merely evidential. But there is a price to pay for this: what occupies the space between the merely conceivable and what might be must somehow depend on circumstance - a notion I so far leave blank except to remark that it is something which may vary while the objects of, respectively, perceptual awareness and awarenessthat remain fixed.

Two things need stressing. First, though Austin distinguishes between evidence and proof, he does not do so by assigning Merkmale to each by which human experience in fact categorises in some unique way into cases of mere evidence and those of proof. The evidence-proof distinction need not, and for Austin cannot, work like that. (His allergy to 'tidy dichotomies'.) This feature is distinctive of all treatments of perceptual knowledge which lie in the Cook Wilson-Prichard tradition post Austinian turn. Second, what this means is that, in the general case, whether someone counts or not as knowing that $\mathrm{P}$ varies with circumstances, where such variation is what occurs with world history fixed. It is still left open pro tem just what circumstances are. Anyway, they are liable to vary while relevant facts of truth-yielding and of truth-transmission remain fixed.

Now, Ayers $(2019,65)$ introduces his distinction between 'primary' and 'secondary' knowledge in part via an example (of secondary knowledge) which is isomorphic with Austin's example, but used to diametrically opposed purpose:

Suppose that a bear has recently passed this way, leaving footprints and droppings, and that I see these, know enough about the local bears to recognize them, notice that the dung is still warm, and conclude truly that there was a bear here recently. 
I substitute an anonymous maven, The Woodsman, for Ayers himself. To transform the described situation into that of Austin's example, we substitute the ursine for the porcine, the sylvan for the merely bucolic, droppings for marks on the ground and food, and finally The Woodsman for Austin himself. For Ayers The Woodsman gets no farther here than mere evidence. But, contra Cook Wilson-Prichard-Austin, he nonetheless gains knowledge. But whereas these others (Austin included) speak of knowledge sans phrase, Ayers adds the modifier 'secondary'. Is 'secondary' perhaps 'soi-disant', as Descartes' 'moral certainty'? Anyway, what justifies restricting The Woodsman's grounds for judging that 'a bear was here recently' to evidence?

Ayers' (2019, 63) presentation of his distinction is somewhat piecemeal. Here, though, the marks of that primary knowledge with which the secondary is to contrast:

Conscious perceptual knowledge is such that those that have it not only have perceptual knowledge of their environment, but also perceptual knowledge that and of how they have that knowledge. They have that logically second-order knowledge without second-order reflection. They have what I have called 'primary knowledge', knowledge gained by being evidently, self-consciously, in direct cognitive contact with the object of the knowledge.

Perceptual awareness may be of what, given that there is this to be aware of, stands in a truth-yielding relation to a certain truth. Entering Benno's rooftop eyrie, Pia spots Ilse, his pet pig, asleep on the sofa. Given that object of visual awareness - what she sees - there is a certain object of awareness-that: that a pig is on the sofa. The awareness Pia thus enjoys (in re the sus scrofa) makes this last recognisable to her. Perception supplies her the grounds of such knowledge, her capacities, inter alia, in re sus scrofa allow her to recognise the grounds these are. The above tells us three things about this. First, that 'perceptual' knowledge that a pig is on the sofa is knowledge that one knows a pig is on the sofa. Second - a point Ayers rightly stresses throughout - perceptual awareness iterates (is 'second-order'): it includes, per se, awareness of one's awareness of its environmental objects. In viewing Ilse, for example, Pia is (visually) aware of relating spatiotemporally to Ilse as she does. Third, one is (self-consciously) in direct cognitive contact with the object(s) of the awareness. Such he presents as the marks of primary knowledge.

The marks of primary knowledge must, inter alia, distinguish it from secondary knowledge (when we know what that is). Not all of this need be thus proprietary. For example, in whatever sense it may be so that to know something 
is to know one knows it, there is no reason to restrict this to cases where one's acquaintance with the grounds of such knowledge is perceptual. And in whatever way perceptual awareness is second-order, it is equally so for Pia in re Ilse and The Woodsman in re the droppings. The relevant factor here is simply perception überhaupt. It is a feature of this that, as he puts it, "[w]e accordingly know what to do - that is, how to manipulate the immediate situation and our relation to what we are perceiving - in order to learn more." $(2019,62)$

Iteration (awareness of awareness) is pervasive throughout perception. But it may seem to do work in awareness-that (knowledge) which it cannot do. One must remember that perceptual awareness is thoroughly extensional. What makes what Pia saw a pig is simply that such is what the object of her visual awareness in fact was. If it was also a bisaro, then what she saw was a bisaro. If it was raised by Austin, then she saw a pig so raised. What of secondorder awareness? Was she aware of awareness of a bisaro? Not (necessarily) if we read that as awareness of her (first-order) awareness being of a bisaro. There are no such automatic paths from the perceptual awareness to the conceptual. The move may tempt. And if we do so read it, we see perceptual awareness becoming, before our very eyes, awareness-that. But such would just be a conjuring trick, the first of two we must take seriously here.

If any mark of primary knowledge distinguishes this from the secondary, such will have to concern the notion 'direct cognitive contact'. And the difference will have to derive from this: that where Pia sees that a pig is on the sofa she actually sees a pig, whereas if the Woodsman sees that a bear has recently been there (where there are now droppings), he does this without seeing a bear there, or anywhere. But, before investigating further, there are pitfalls to watch out for. Ayers speaks of 'direct cognitive content' with the 'object of knowledge'. But in English and German (not in Dutch) the word 'object'/'Gegenstand' is polysemous. There is the object of a verb (or capacity, or exercise thereof), thus, in the case of knowledge, of awareness-that. And then there are objects in logikgemäss sense: whatever can combine with a proper predicable to form a way it takes a whole thought to represent things being. The Dutch 'voorwerp' fits only this last use. Collidables - spatially bounded items with a temporal career, e.g., pigs, bears, sofas, ursine droppings, are objects in this sense. Such things are eligible objects of perceptual, e.g., visual, awareness, but not of awareness-that. (Nor are objects of awareness-that potential objects of perceptual awareness.)

So, an object of awareness-that is, e.g, that a pig is on the sofa, or that a bear was recently here. An object in logikgemäss sense is, e.g., the pig, the sofa, those droppings, a pig-on-sofa complex. An object of awareness that (knowledge) 
is never an object of perceptual awareness, on either reading of 'object'. Such things as pigs, bears, sofas and dung may be one point at which the example of Austin and the example of the Woodsman differ - in a way which must (for Ayers) make a difference, somehow, between 'primary' and 'secondary' knowledge. Is it, then, objects in logikgemäss sense with which one must be in 'direct cognitive contact' in primary knowledge? If so, what fixes, in a given case, which ones these are?

Our sample objects of awareness-that - that a pig is on the sofa, that a bear has been recently present - raise a further issue. Each is an existential generalisation. Such indicates an object only indefinitely, excuses itself from making any given one the one on which its truth turns. (I bracket the issue of the sofa.) Existential generalisations are about concepts. What truth requires in each present case is, in the first, that the concepts to be a pig and to be on the sofa are jointly satisfied by something, in the second that ditto for the concepts to be a bear and to be recently present. To be perceptually aware of what yields such truth, one must be perceptually aware of things being such as for those concepts to be jointly satisfied. Of what object (logikgemäss sense), if any, must one be aware if he is to do this? Anyway, none such is identified by the thought itself. There may be a temptation, perhaps felt by Ayers, to answer: In the first case, some relevant pig; in the second some relevant bear'. But let us hold fire.

To review, perceptual awareness is thoroughly extensional where awarenessthat is not. It is from a particular case - a gradual, partial, unfolding of the fullness of time - to a generality of which that case is in fact an instance. So a transition from the one to the other is never effected, though it may be permitted, by perceptual awareness alone. It must always exploit a capacity to recognise an object of perceptual awareness as so instancing (or not). The work of perceptual awareness itself is just to make such recognisable (to one suitably equipped). Here we may think of there being two kinds of case. In the one, awareness-that is achieved merely by recognition of a truth-yielding transition: that arrangement of objects in Benno's salon is one thing which would count as a pig on a sofa. In the other, truth-yielding takes us only so far: some further truth-transmitting step(s) must be taken. If we read a bit of psychology into this, we might suppose that someone who achieved awareness-that in fact did it in the one way or the other, or that given perceptual awareness may afford only the one route or the other to a given bit of awareness-that. But again hold fire. In any case (of knowledge überhaupt) one remark of Ayers' anyway holds: to know (to be perceptually aware) is to be prepared to act accordingly, to relate what is thus known to oneself. 
Returning to The Woodsman (or, to be fair, Ayers in woodsman's clothing), we now note that Ayers does not quite keep his powder dry. For he assumes that the case, The Woodsman, takes this shape: The Woodsman (Ayers) sees indications of recent ursine presence, mounting evidence of this. He then takes one or more inferential steps, in effect, 'The evidence is very strong (I know fresh droppings), therefore a bear was recently here.' Ayers calls this 'inference to the best explanation'. And he finds this worth calling 'secondary knowledge', that last word used au pied de la lettre, even though based on grounds consistent with being wrong. Cook Wilson and Austin, of course, will have none of this. If all the Woodsman has to go on are 'indications' of bear, then all he has is evidence in the usual Anglo (legal) sense of that word, and thus no knowledge at all, at least in re ursine presence. Here Austin reverso. Austin: Mere evidence is not proof. So, if seeing a pig can furnish proof of same, not all perceptual awareness is of mere evidence. Ayers: sometimes mere indications make for what passes for knowledge, therefore some kinds of knowledge (secondary as they may be) rest on mere evidence (au pied de la lettre).

Two cases: You and I are out for a constitutional in the reserve (walking off the trous Normandes). (I assume your forestry is on a par with mine.) On the trail before us we spot some steaming droppings. From the looks, we'd say, they may well be bear. So a bear may well have been recently here. What we have formed may well be rational, but then rational belief. 'May well' disclaims knowledge that. Now the Woodsman (following close behind without making his presence known). Spotting the droppings he concludes, 'Within the last twenty minutes a three year old male European black bear was here.' Mere belief? This man knows his droppings. But do truth-yielding and truthtransmission inevitably mix here?

Frege enters the mix again. One thing he always insisted on is that a thinkable (Gedanke) is multiply decomposable, in different ways out of different elements. Correlatively, there is no unique array of logikgemäss objects (even modulo indefinite indication) which are the ones the thought represents as being thus and so. In the present instance the (candidate) object of the Woodsman's awareness-that can also be expressed thus: 'An event of suffering recent ursine presence/circumstance of there being such presence is occurring/obtains.' (It is irrelevant that the Woodsman is unlikely to put it quite that way.) Now, the suffering bit of trail, droppings still steaming, is clearly visible, and - to The Woodsman's eye - clearly recognisable for what it thus is. This thus permits him (as it would not $u$ s) to recognise what he sees as satisfying the concept locus of recent ursine presence.

Putative distinctions between 'primary' and 'secondary' knowledge are not to be drawn as Ayers attempts. Ayers $(\mathbf{2 0 1 9}, 65)$ writes, 
What is simply evident, or enough of it, can so serve as 'the evidence' for a conclusion as to make that conclusion itself evident and certain, if not 'primary knowledge' in the full sense.

But given Ayers' marks of the notion primary, there is no reason (as such) to deny the Woodsman primary knowledge, awareness-that a bear was recently present. That he caught no bear in flagrante delicto is not eo ipso such reason. And if we could not do so, we would be left with no reason to call the Woodsman's status here knowledge at all.

One moral of the present tale concerns the value, and the point, of Frege's injunction against reading the logical directly into the psychological. The object of given perceptual awareness is articulable into presences (of determinate objects, events, conditions, etc.) in many different ways. There are, correlatively, many different paths from such object to various objects of awareness-that, paths by which such might be recognisable to someone with the right capacity to make something of what he is perceptually presented with. Philosophy is in the business of charting such paths in terms of the phenomena truth-yielding and truth-transmission. What is thus uncovered cannot be read in any direct way into an account of the steps by which a given thinker attained to given awareness-that.

A second, correlative, moral is the Austinian turn itself. What feats of recognition a given thinker performed (in the course of given experience) and on what grounds, so by what steps, he achieved this, are not psychological questions, or certainly not purely so. For, as Austin points out, charting the space between what is merely conceivable and what might be is something which can be done at all only bit-wise and relative to the circumstances in which what is so judged is so to count. Such is the moral of Austin's example.

\section{7}

\section{Disjunctivism}

The first disjunctivism to bear the name (vide Hinton 1967) concerned perception, a form of success, perceptual awareness of one's surroundings. Here the idea starts from the concession that for any such success, say, seeing a pig on a sofa, there is such a thing as a perfect illusion thereof, which, if suffered, would have been indistinguishable from the success thus had. So for every true ascription to someone of such success, there is a true disjunction: that subject either enjoyed that success or suffered such illusion. Disjunctivism about perception now claims two things: First, there is not, or no reason to think there is, an identifiable common factor (the 'highest'): an independently identifiable 
something which would have been experienced in either disjunct, to experience precisely which would be to enjoy just the perceptual awareness one did if enjoying that success, there being (as near as matters) nothing for a ringer for the disjunction to be. Second, for every true first disjunct - for every such success - there is such a disjunction with its companion ringer. So, conversely, the existence of such disjunction does not rule out the truth of its first disjunct.

There is a parallel disjunctivism about knowledge (vide McDowell 1982). Here one disjunct ascribes a given bit of knowledge, that $\mathrm{P}$, to someone. In the other disjunct the subject suffers a perfect illusion of thus having such knowledge: to him, all seems just as it would have been, were the first disjunct true. But it is mere seeming. It seems to the subject that he has all the grounds for taking it that $\mathrm{P}$ which, in the first disjunct, he does have, and these seem to him to prove that $\mathrm{P}$, as in the first disjunct they did. But, undetectably by him, either he does not have (all) these grounds, or they do not prove. Some versions of such disjunctivism may identify a highest factor whose existence they deny. But the most crucial thing for present purpose is just the insistence that the existence of such disjunction does not show that its first disjunct is not true (show the subject not to know). There are two different cases.

So for each success its ringer. But this does not show the success not to be had. As Austin insists, 'I might be wrong' does not, and cannot, mean 'I am a fallible human being', nor merely that it is conceivable that I should have been wrong. We are about to take the Austinian turn. The price of this, we have seen, is that those statuses, knowing (being aware) that $P$, having proof, are not to be conceived as identifying two disjoint categories into just one of which each candidate case of knowledge/awareness-that fits, fertig. In such matters what fits where must depend on circumstance in such way that what sometimes counts as such enjoyment - that very case - may sometimes not. (Austin's aversion to tidy dichotomies.)

McDowell is, or tries to be, a disjunctivist sans Austinian turn, or at least sans occasion-sensitivity. He formulates his disjunctivism in somewhat different ways on different occasions. Here is one which Ayers quotes twice (McDowell 2011, 31, in Ayers 2019, 81 and 191, except first sentence 81 only):

[I]f a perceptual state consists in a subject's having a feature of her environment perceptually present to her, that gives the lie to the assumption that a perceptual state cannot warrant a belief in a way that guarantees its truth. If a perceptual state makes a feature of the environment present to a perceiver's rationally self-conscious awareness, there is no possibility, compatibly with someone's being in that state, that things are not as 
the state would warrant her believing that they are, in a belief that would simply register the presence of that feature of the environment.

Ayers joins such philosophers as Crispin Wright and Tyler Burge in insisting that the demands on enjoying such status are insuperably, anyway implausibly, strong. McDowell, Ayers says $(2019,192)$,

calls on the notion of perception as 'direct presence in experience' or ... presence 'to a perceiver's rationally self-conscious awareness'. That ... seems intended to build into a concept of perception (or 'perceptual presence') the condition that if we truly claim to perceive that $\mathrm{P}$, there is no epistemic possibility that not-P.... If someone sees that $\mathrm{P}$, it cannot fail to be the case that $\mathrm{P}$. But for a claim to perceptual knowledge to be that safe, not only must there be no epistemic possibility of defeat relative to the evidence available now, the claim must be indefeasible by fresh evidence in the future.

"For a claim ... to be that safe ...": Precisely what sort of safety does Ayers have in mind? An environment to think about, Frege reminds us, brings with it liability to error. But it is a necessary condition both on perceptual awareness and on there being truths for this to make recognisable. Given such liability it is always conceivable that one should prove (or have proven) wrong. There is such a thing as that. It is part of disjunctivism that the epistemic statuses it posits require no more safety than such liability allows for.

In the quote Ayers saddles McDowell with two insistences in re his posited status ('presence to the perceiver of an environmental feature'). One of these, 'if someone sees that $\mathrm{P}$, it cannot fail to be the case' is simple grammatical truism, obscured for Ayers by misreading 'see that' as source of a ground for holding that $\mathrm{P}$. The other is key: If someone truly claims to 'perceive' that $\mathrm{P}$ there is no 'epistemic' possibility that not-P. The word 'epistemic' is key. One might read 'epistemically possible' as notational variant of Austin's 'might be'. We then have something McDowell may harmlessly insist on. Again in point of grammar you cannot take a feature of the world to be revealed to you, credit yourself with awareness-that if you suppose that you might be wrong (that it might be absent). Nor could we, in so supposing, correctly attribute such success to you.

Epistemic possibility could be read as governed by the principle: There is epistemic possibility that not-P where proof that $\mathrm{P}$ would still be called for. $\mathrm{P}$, if so, would stand at the terminus of given truth-yielding and/or 
truth-transmitting transitions. But that it so stands has not yet been made recognisable. Plausibly, where something is perceptually present to a thinker in McDowell's sense, there is no epistemic possibility in this sense that it is not. Pia sees a pig on a sofa. If this is what she does, then that a pig is on the sofa stands at the terminus of a step of truth-yielding from the object of her perceptual awareness. But so far she need not be aware of this being what she is doing. So far, then, she does not yet enjoy the status McDowell posits. But suppose she recognises what she sees as what it thus is. If she really does this, then there is no epistemic possibility that there is no pig on the sofa. That step of truth-yielding is now proof, impervious to proving otherwise. Pia would thus enjoy the status McDowell posits: There is no possibility that things are not as she recognises them to be.

To say that this fact of porcine sofa-presence is 'perceptually present' to Pia is not to say that it is inconceivable that things should have been otherwise, e.g., that it should have been a genetically modified aardvark. What is conceivable is not per se to the point. Such is intrinsic to disjunctivism (as here presented). It is also intrinsic to - a lynchpin of - the Austinian turn. These two things are one on the present account of the matter. Ayers helps us see how crucial this shared point is to disjunctivism's success. Minding our modals as Austin does, we find there to be no cause for taking the status McDowell insists on to require any sort of superpowers. If there were reason to suppose that genetically modified aardvarks might be on the loose, then, perhaps, Pia would not be positioned to enjoy this status. If we (or she) supposed she was, we, or she, would be mistaken in this. But it does not follow from the fact that I can intelligibly tell such tale (if I can) that Pia does not enjoy the status.

For Pia to take herself ( $d e$ re $)$ to enjoy McDowell's status is, of course, one thing, for us to take her to, another. The first may be a necessary condition for enjoying the status but also of course not a sufficient one. If we see that more proof would be required before one in Pia's circumstances could count as aware that a pig is on the sofa, then we also thereby see that Pia does not enjoy the status. Mutatis mutandis for taking more proof thus to be needed. If we would need more proof before we could correctly take ourselves to be aware that there was (or was not) a pig on the sofa, then, though for all that Pia might enjoy the status, we are not (yet) in a position to see that she enjoys the status, though perhaps we can see that, in any case, no matter what, Pia does not.

Might not be and conceivably might not have been are two very different things. This much of Austin's turn is inherent in any disjunctivism, in the very nature of the disjunctions it treats. It is something McDowell needs to exploit to avoid charges of attributing superpowers to us. But what of tidy dichotomies? 
Here, I suggest, McDowell has chosen to remain agnostic. Austin's aversion to these is an expression of his conception of the way the application of a concept, e.g., the presently relevant notion of proof, or of awareness-that, depends on circumstance. As Austin (1962, 120-121) writes,

[If] you just take a bunch of sentences (or propositions ...), impeccably formulated in some language or other, there can be no question of sorting them out into those that are true and those that are false, for ... the question of truth and falsehood does not turn only on what a sentence $i s$, nor yet on what it means, but on, speaking very broadly, the circumstances in which it is uttered.

Once again that place-holder 'circumstance'. So far we have two variables in view. Whether Pia enjoys McDowell's status depends, of course, on her circumstances. Whether she is correctly judged by us to do so, depends, inter alia, on ours. Whether we are in a position to judge her so, of course, depends. But what about the truth of what we judge? Once again Austin's aversion to tidy dichotomies. Disjunctivism per se insists on a line between 'might' and 'conceivable'. Whether someone falls on the knowledgeable side of an epistemic disjunction for some given object of awareness-that depends on just where this line is to be drawn. But how is this to be decided? Must the disjunctivism itself deliver verdicts on all (or any) such matters? Or what role remains for circumstance?

One way to scout the territory is to consider the relation between knowledgeability and assertion. When one asserts (baldly), he not only represents things as per the thought expressed, but also represents himself as authoritative on the subject, in a (well-exploited) position to know. For all of this his audience may or may not rate him as authoritative. For all of which, they may or may not be correct in so doing. If correct, then, at the least, in those circumstances the speaker does count, casu quo not, as authoritative (knowledgeable), thus as aware that, say, Benno has a pet pig. Now hold the speaker, his awareness of the world and the proposition constant. Does the rightness of his claim to authority also thus remain constant across occasions for so asserting?

Pia frequents Benno's penthouse often enough to be familiar with the resident ménage. If she tells us that Benno has a pet pig, such may be patently an expression of awareness-that. But a responsible audience might have cogent reason to suspect, say, that Benno's 'pig' is really a GM aardvark. Suppose Pia were to assert to this audience that Benno's pet is a pig. She would have spoken truth on just the issue of concern to them. Still, she would have misinformed. For she also presented herself as authoritative. If she were, suspicions would 
be put to rest. But her word here cannot weigh as proof. Pia lacks the required authority to transmit. She is not what here would count as knowledgeable. One dimension along which for the status awareness-that to vary.

The idea is: what it would be to be authoritative varies with circumstance for so judging one. If we find that Pia 'really is' authoritative, such is just one perspective circumstance might offer. The present aim is to identify, not to prove, the point; to complete Austin's turn. It out of view, McDowell's halfturn (Hinton transmitting so much Austin) leaves Ayers unmoved. He thus raises the question whether it must be full turn or none at all. Full, perhaps, if grounds of knowledge are to align aright with grounds of truth.

\section{References}

Austin, John L. 1946. "Symposium: Other Minds II." Proceedings of the Aristotelian Society, Supplementary Volume 20, 148-187. Reprinted as "Other Minds 1." In: Austin, John L. 1979, Philosophical Papers, Oxford: Oxford University Press, 76-116. Austin, John L. 1962. Sense and Sensibilia. Oxford: Oxford University Press. Ayers, Michael 2019. Knowing and Seeing. Oxford: Oxford University Press. Cook Wilson, John 1926. Statement and Inference with Other Philosophical Papers, 2 vols. Edited by A. S. L. Farquharson. Oxford: Clarendon Press.

Frege, Gottlob 1882. "xxx/1 Frege an Marty." In: Wissenschaftlicher Briefwechsel, 1st edition 1976, edited by Gottfried Gabriel, et al., Hamburg: Felix Meiner, 163-165.

Frege, Gottlob 1884. Die Grundlagen der Arithmetik. Breslau: Koebner.

Frege, Gottlob 1897. "Logik." In: Nachgelassene Schriften, end edition 1983, edited by Hans Hermes, et al., Hamburg: Felix Meiner, 137-163.

Frege, Gottlob undated (1906 or earlier): "17 Kernsätze zur Logik." In: Nachgelassene Schriften, and edition 1983, edited by Hans Hermes, et al., Hamburg: Felix Meiner, 189-19o.

Frege, Gottlob 1906. "Einleitung in die Logik." In: Nachgelassene Schriften, and edition 1983, edited by Hans Hermes, et al., Hamburg: Felix Meiner, 201-212.

Frege, Gottlob 1914. "Logik in der Mathematik." In: Nachgelassene Schriften, 2nd edition 1983, edited by Hans Hermes, et al., Hamburg: Felix Meiner, 219-270.

Frege, Gottlob 1918. "Der Gedanke." In: Beiträge zur Philosophie des deutschen Idealismus, Band 1, Nr. 2, 1918-1919, 58-77.

Hinton, John M. 1967. “Visual Experiences." Mind 76, 217-227.

McDowell, John 1982. "Criteria, Defeasibility and Knowledge." Proceedings of the British Academy 68, 455-479.

McDowell,John 2011. Perception as a Capacity for Knowledge. Milwaukee, WI: Marquette University Press. 
Prichard, Harold A. 1950. "History of the Theory of Knowledge (1932). Descartes's Meditations." In: Knowledge and Perception (essays and lectures), Oxford: Oxford University Press, 71-103.

Putnam, Hilary 1977. "Realism and Reason." Proceedings and Addresses of the American Philosophical Association 50 (6), 483-498. 